\title{
SISTEM INFORMASI PENJUALAN BIBIT DURIAN BERBASIS WEB PADA KELOMPOK TANI MAJU MAKMUR DESA ALASMALANG
}

\author{
Vembria Rose Handayani ${ }^{1}$, Indah Sulistyowati ${ }^{2}$, Elly Muningsih ${ }^{3}$ \\ Universitas Bina Sarana Informatika ${ }^{1,2,3}$

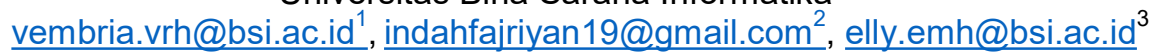

\begin{abstract}
Abstrak - Berkembangnya ilmu pengetahuan dan teknologi informasi membuat manusia mencari cara yang cepat untuk memudahkan kegiatan usaha. Salah satu caranya adalah menggunakan teknologi informasi berupa website. Kelompok Tani Bibit Durian Maju Makmur adalah sebuah kelompok tani yang bergerak dibidang tanaman dan berada di desa Alasmalang Kabupaten Banyumas. Namun penjualan dan pemasaran bibit durian pada Kelompok Tani Maju Makmur belum memanfaatkan adanya website ataupun penggunaan e-commerce karena keterbatasan pengetahuan tentang internet. Para petani hanya menggunakan handphone untuk sarana penjualan maupun pemasaran. Dengan pembuatan website untuk Kelompok Tani Maju Makmur dapat mengatasi masalah transaksi penjualan dan pemasaran bibit durian. Perancangan sistem informasi berbasis website ini menggunakan Dreamweaver CS6, PHP, HTML, dan XAMPP. Metode yang digunakan dalam pengembangan sistem ini yaitu dengan model waterfall. Untuk pengujian unit menggunakan Black Box Testing. Dengan keberadaan website dapat membantu konsumen atau pelanggan dalam mengakses informasi kapan dan dimana saja, serta bisa menjadi sarana promosi untuk memperluas jangkauan pemasaran produk dan menambah penghasilan.

Kata Kunci : Website, E-commerce, Sistem Informasi, Kelompok Tani
\end{abstract}

\begin{abstract}
The development of science and information technology makes people looking for a quick way to facilitate business activities. One way is to use information technology in the form of websites. The Durian 'Maju Makmur Farmers' Farmer Group is a farming group engaged in plants and located in the village of Alasmalang Banyumas district. But the sale and marketing of durian seeds in the farmer group 'Maju Makmur' have not utilized the website or use the e-commerce because of limited knowledge about the internet. The farmers only use mobile phones for sales and marketing advice. By creating a website for the farmer group 'Maju Makmur' can solve the problem of durian seed sales and marketing transactions. This website-based information system design uses Dreamweaver CS6, PHP, HTML, and XAMPP. The method used in the development of this system is the waterfall model. For unit testing using Black Box Testing. The existence of the website can help consumers or customers to access information anytime and anywhere and can be a promotion tool to expand the reach of marketing products and increase revenue.
\end{abstract}

Keywords: Website, E-commerce, Information System, Farming Group

\section{PENDAHULUAN}

Perkembangan Teknologi Informasi (TI) dalam sekarang ini sudah sedemikian pesatnya. Hal ini menuntut perusahaan untuk selalu mengikuti perkembangan tersebut. Perkembangan ini mempunyai dampak signifikan terhadap perusahaan baik perusahaan besar maupun kecil. Perusahaan yang memanfaatkan teknologi informasi dengan baik maka akan dapat memimpin persaingan dalam dunia bisnis. Perusahaan yang memanfaatkan teknologi informasi dapat memberikan pelayanan terbaik kepada pelanggan atau konsumen agar bisa bertahan dalam persaingan yang semakin ketat. Jadi pada intinya kebutuhan akan TI sudah menjadi kebutuhan dasar bagi setiap perusahaan, terutama dalam menjalankan aktivitasnya. Khususnya internet, teknologi yang tidak mengenal batas ruang dan waktu ini sangat dibutuhkan dalam dunia yang semakin global.
Internet memberikan kesempatan bagi perusahaan atau pengguna diseluruh dunia melakukan komunikasi dan menggunakan informasi yang ada didalamnya secara bersama-sama. Internet dapat diartikan sebagai jaringan komputer luas dan besar yang mendunia, yaitu menghubungkan pemakai komputer dari suatu negara ke negara lain di seluruh dunia, dimana di dalamnya terdapat berbagai sumber daya informasi dari mulai yang statis hingga yang dinamis dan interaktif. Internet merupakan sebuah jaringan (Internet Protokol) yang terdiri dari beberapa komputer yang sudah terkoneksi ke dalam jaringan global (Sholechul Azis dan Ikhsan Maulana dalam (Sari \& Prasetiawati, 2020)). Dengan internet para pelaku usaha dan konsumen, tidak perlu lagi melakukan transaksi dengan cara saling berhadap-hadapan atau saling bertemu atau secara manual. Dengan menggunakan teknologi internet para konsumen bisa langsung 
melakukan transaksi jual beli, memesan barang atau transaksi lainnya antar para pengusaha di penjuru dunia. Dengan internet, semua transaksi menjadi terasa lebih praktis, mudah, cepat, efektif dan efisien.

Salah satu strategi perusahaan atau perorangan untuk mempromosikan produk yang berkaitan dengan teknologi informasi adalah memanfaatkan website dalam sistem penjualan dan pemasaran produk. Salah satu sistem jual beli dengan media internet adalah ecommerce. E-commerce adalah suatu konsep yang biasa digambarkan sebagai proses jual beli barang atau jasa pada alamat website Word Wide Web atau proses jual beli barang atau pertukaran produk, jasa, dan informasi melalui jaringan informasi termasuk internet, dan e-commerce juga bisa melakukan kegiatan bisnis yang dijalankan secara elektronik melalui suatu jaringan internet atau kegiatan jual beli barang atau jasa melalui jalur komunikasi digital berupa komputer, laptop dan smartphone (Himawan, Saefullah dan Santoso dalam (Juniansyah, Susanto, \& Wahyudi, 2020)). Namun, untuk wilayah daerah kecil atau pedesaan masih banyak yang belum memanfaatkan adanya sistem informasi berbasis website ataupun penggunaan ecommerce termasuk petani Bibit Durian Tani Makmur yang ada di desa Alasmalang Kabupaten Banyumas. Karena keterbatasan pengetahuan tentang internet. Para petani hanya menggunakan handphone untuk sarana penjualan dan pemasaran. Dengan adanya masalah tersebut Petani Bibit Durian Alasmalang membutuhkan sebuah sarana teknologi informasi untuk membantu memasarkan dan menyampaikan informasi produk serta harga bibit durian pada konsumen. Beberapa peneliti melakukan penelitian berkaitan dengan sistem informasi penjualan khususnya yang berkaitan dengan bidang pertanian dan juga pelaku usaha banyak yang belum menggunakan serta belum memanfaatkan teknologi informasi berbasis website. Hasil penelitian yang dilakukan oleh (Rhiyan Edyal, 2016) bahwa dengan adanya aplikasi penjualan kelapa sawit mampu meningkatkan pendapatan petani, karena waktu dan jarak untuk pengambilan DO (Delivery Order) dapat dipangkas, untuk validasi data akan lebih akurat dan memperoleh info transaksi dan harga TBS (Tandan Buah Segar). Menurut penelitiian yang dilakukan oleh (Nasser, 2017) bahwa program aplikasi yang telah dibuat agar menghasilkan informasi barang dan menjalin interaksi antara user pengguna website. Penelitian yang dilakukan oleh (Arman Arman, Elizamiharti, 2019) memperoleh hasil bahwa aplikasi ini dapat memberikan kemudahan bagi pihak manajemen Salman KS Flowers, admin, bagi karyawan dan juga bagi pelanggan dalam bertransaksi dalam proses pemesanan tanaman hias dimana pun pelanggan itu berada. Selain itu dengan adanya aplikasi ini pelanggan dapat mendapatkan informasi tentang informasi tanaman hias secara mudah dan cepat dibandingkan dengan cara convesional sebelum sistem ini dirancang. Penelitian yang dilakukan oleh (Aprizal, 2016) tentang sistem informasi penjualan benih padi pada Balai Pengkajian Teknologi Pertanian dimana selama ini sistem informasi yang selama ini berjalan masih dilakukan secara manual yaitu pelanggan masih harus datang ke kantor untuk membeli benih padi sehingga diusulkan untuk melakukan Pengembangan Sistem Informasi Penjualan Benih Padi pada Balai Pengkajian Teknologi Pertanian (BPTP) SUL-SEL yang diharapkan nanti dapat memberikan kemudahan dalam artian pengolahan data dapat berlangsung cepat, tepat, dan aman. Dan penelitiannya menghasilkan kesimpulan bahwa dengan adanya aplikasi pengolahan data pada ruang kerja tertentu akan lebih memudahkan satuan kerja agar lebih maksimal dalam hal pengolahan data.

Berdasarkan pemaparan diatas, terutama khususnya permasalahan yang terjadi pada Kelompok Tani Bibit Durian Maju Makmur maka penelitian ini berupaya untuk merancang aplikasi berbasis website dengan menggunakan metode waterfall. Dengan keberadaan website dapat membantu konsumen atau pelanggan dalam mengakses informasi kapan dan dimana saja dengan mudah serta dapat mempermudah dalam melakukan transaksi. Bagi pihak pelaku usaha, bisa menjadi sarana promosi untuk memperluas jangkauan pemasaran produk dan menambah penghasilan penjualan.

\section{METODOLOGI PENELITIAN}

Menurut Rosa dan Shalahuddin dalam (Hariyanto \& Meidiany, 2018), "Metode pengumpulan data "Model SDLC air terjun (waterfall) sering juga disebut sekuensial linier (sequential linier) atau alur hidup klasik (classic life cycle)".

Menurut Rosa dan Shalahuddin dalam (Hariyanto \& Meidiany, 2018), model air terjun menyediakan pendekatan alur hidup perangkat lunak secara sekuensial atau terurut dimulai dari analisis, desain, pengodean, pengujian, dan tahap pendukung (support):

1. Analisis kebutuhan perangkat lunak

Proses pengumpulan kebutuhan dilakukan secara intensif untuk menspesifikasi kebutuhan perangkat lunak agar dapat dipahami perangkat lunak seperti apa yang dibutuhkan oleh user. 
Spesifikasi kebutuhan perangkat lunak pada tahap ini perlu di dokumentasikan.

\section{Desain}

Desain perangkat lunak adalah proses multi langkah yang fokus pada desain pembuatan program perangkat lunak termasuk struktur data, artsitektur perangkat lunak, representasi antarmuka, dan prosedur pengkodean. Tahap ini mentranslasi desain agar dapat diimplementasikan menjadi program pada tahap selanjutnya. Desain program perangkat lunak yang dihasilkan, pada tahap ini juga perlu didokumentasikan.

3. Pembuatan Kode Program

Desain harus ditranslasikan kedalam program perangkat lunak. Hasil dari tahap ini adalah program komputer sesuai desain yang telah dibuat pada tahap desain.

4. Pengujian

Pengujian fokus pada perangkat lunak secara dari segi lojik dan fungsional dan memastikan bahwa semua bagian sudah diuji. Hal ini yang dilakukan untuk meminimalisir kesalahan (error) dan memastikan keluaran yang dihasilkan sesuai dengan yang diinginkan.

5. Pendukung (Support) atau Pemeliharaan (Maintenance)

Tidak menutup memungkinkan sebuah perangkat lunak mengalami perubahan ketika sudah dikirimkan ke user. Perubahan bisa terjadi karena adanya kesalahan yang muncul dan tidak terdeteksi saat pengujian atau perangkat lunak harus beradaptasi dengan lingkungan yang baru. Tahap pendukung atau pemeliharaan dapat mengulangi proses pengembangan mulai dari analisis spesifikasi untuk perubahan perangkat lunak yang sudah ada, tapi tidak untuk membuat perangkat lunak baru.

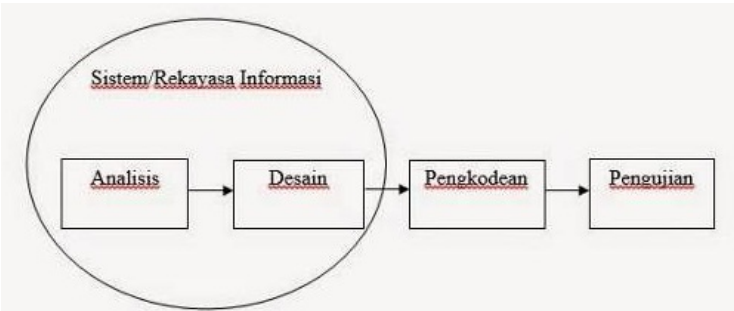

Sumber: Rosa A.S dan M. Shalahuddin dalam (Hariyanto \& Meidiany, 2018)

Gambar 1. Ilustrasi Model Waterfall

\section{HASIL DAN PEMBAHASAN}

\section{Analisis Kebutuhan}

a. Analisis Kebutuhan Sistem

Analisis kebutuhan sistem mencangkup hak akses untuk Visitor, Member, dan Admin. Sistem informasi ini dibuat agar dapat diakses oleh beberapa tingkatan pengguna. Masing-masing pengguna akan memperoleh menu yang terbatas sesuai hak asesnya. Hak akses tersebut diantaranya:

1) Visitor

a) Visitor mendapat informasi mengenai profil perusahaan.

b) Visitor mendapat informasi mengenai produk.

c) Visitor mendapat informasi mengenai kontak perusahaan.

d) Visitor mendapat informasi galeri produk.

e) Visitor mendapat layanan testimoni.

2) Member

a) Member mendapat akses login dan akses password.

b) Member mendapatkan akses informasi produk.

c) Member dapat melakukan transaksi pembelian produk.

d) Member mendapat akses profil tentang perusahaan.

e) Member mendapat akses cara pemesanan.

f) Member mendapat akses tentang konfirmasi pembayaran.

3) Admin

a) Admin mendapat akses untuk mengelola website.

b) Admin mendapat akses mengenai daftar member.

c) Admin mendapat akses mengelola transaksi pemesanan produk.

d) Admin mendapat akses testimoni.

e) Admin mendapat akses mengenai manajemen produk, profil dan galeri.

b. Kebutuhan Non Fungsional

Kebutuhan non fungsional adalah kebutuhan yang berisi tentang pendukung dari pembuatan website yaitu:

1) Kebutuhan Hardware

Kebutuhan perangkat keras (hardware) yang dibutuhkan dalam pembuatan website Sistem Informasi Penjualan Bibit Durian Kelompok Tani Maju Makmur antara lain:

a) Monitor : WSVGA 10.1

b) Prosesor : Intel Inside CORE i5

c) RAM : 4,00 GB (Giga Byte)

c. Hardisk : $320 \mathrm{~GB}$

f) Mouse dan Keyboard

2) Kebutuhan Software

Kebutuhan perangkat lunak (software) yang dibutuhkan dalam pembuatan website Sistem Informasi Penjualan Bibit Durian Kelompok Tani Maju Makmur antara lain:

a) Sistem Operasi : Windows 8

3) Aplikasi : Adobe Dreamweaver CS6

b) Web Browser : Google Chrome

c) HTML, PHP, Jquery

d) XAMPP Versi 3.2.2

\section{Rancangan Basis Data}

a. Entity Relationship Diagram (ERD) 


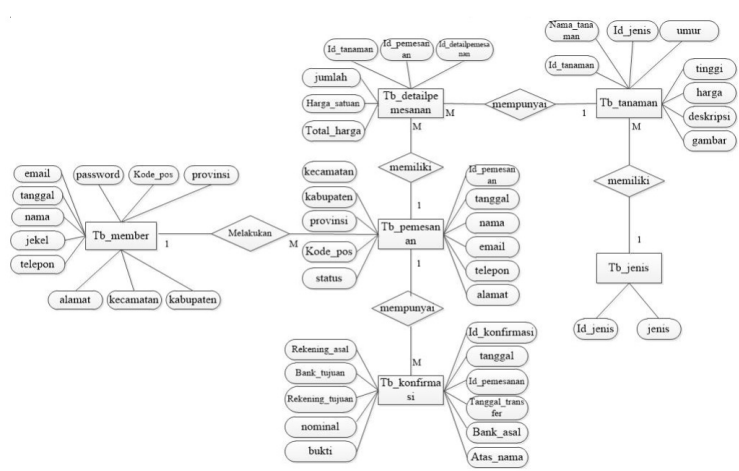

Sumber: Hasil Penelitian 2019

Gambar 2. Rancangan Entity Relationship

Diagram (ERD)

b. Logical Record Structure (LRS)

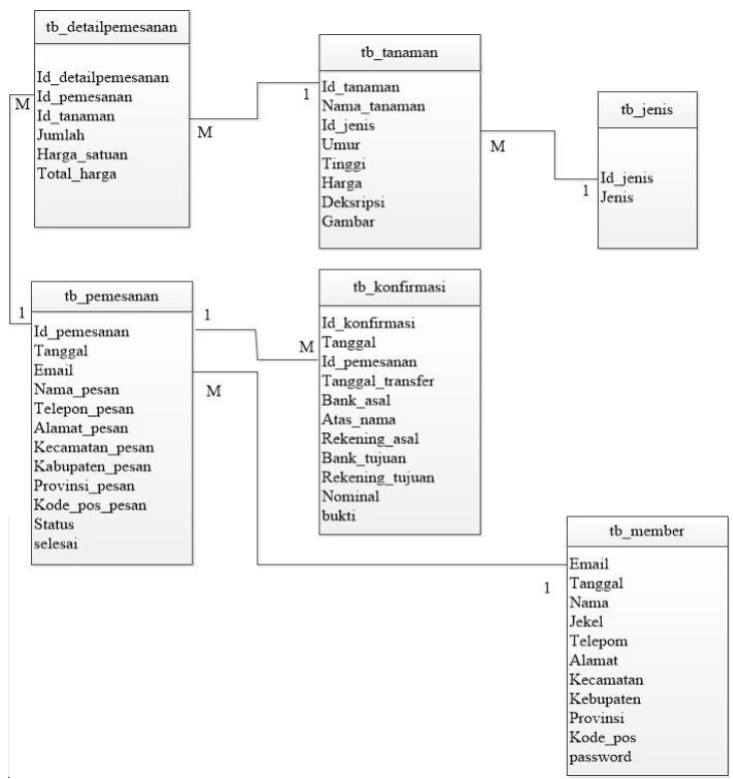

Sumber: Hasil Penelitian 2019

Gambar 3. Rancangan Logical Record Structure (LRS)

\section{Rancangan Struktur Navigasi}

Struktur navigasi yang digunakan pada website ini yaitu sebagai berikut:

1. Struktur Navigasi Halaman Administrator

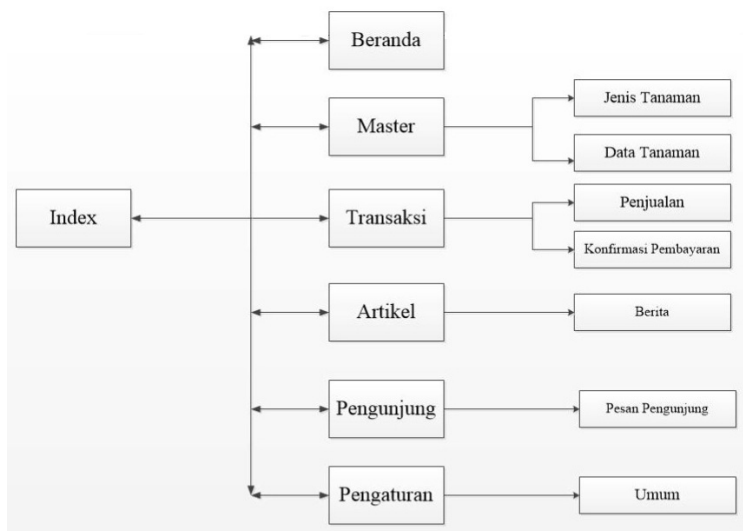

Sumber: Hasil Penelitian 2019

Gambar 4. Struktur Navigasi Halaman Administrator
2. Struktur Navigasi Halaman Visitor

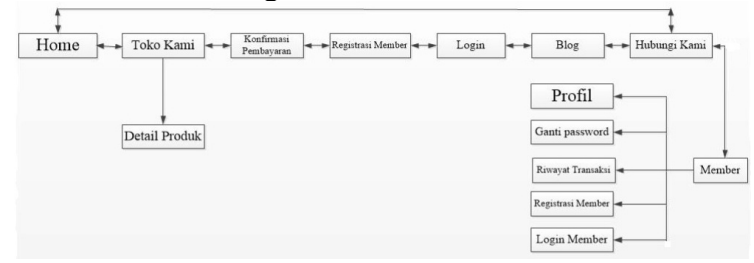

Sumber: Hasil Penelitian 2019

Gambar 5. Struktur Navigasi Halaman Visitor

3. Struktur Navigasi Halaman Member

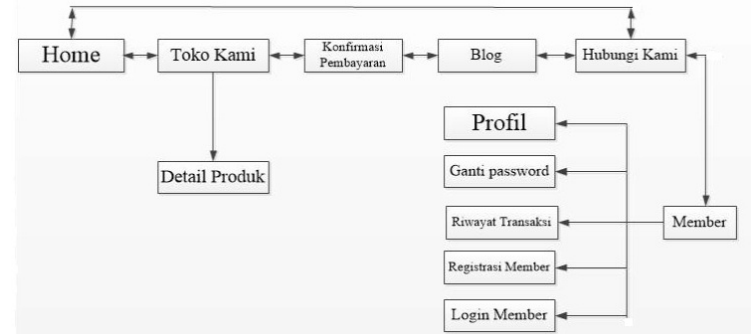

Sumber: Hasil Penelitian 2019

Gambar 6. Struktur Navigasi Halaman Member

\section{Implementasi}

a. Home
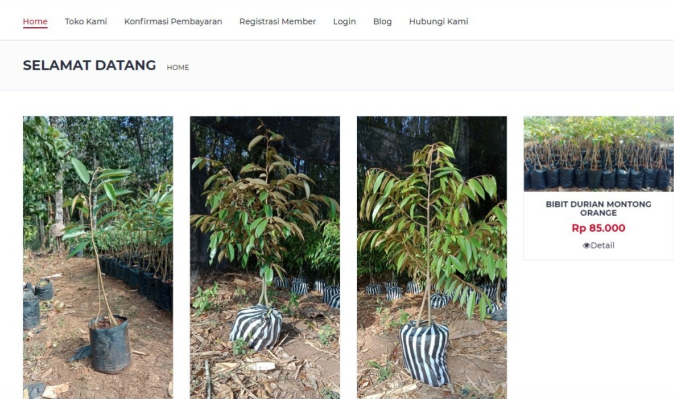

Sumber: Hasil Penelitian 2019

Gambar 7. Implementasi Home

b. Registrasi Member

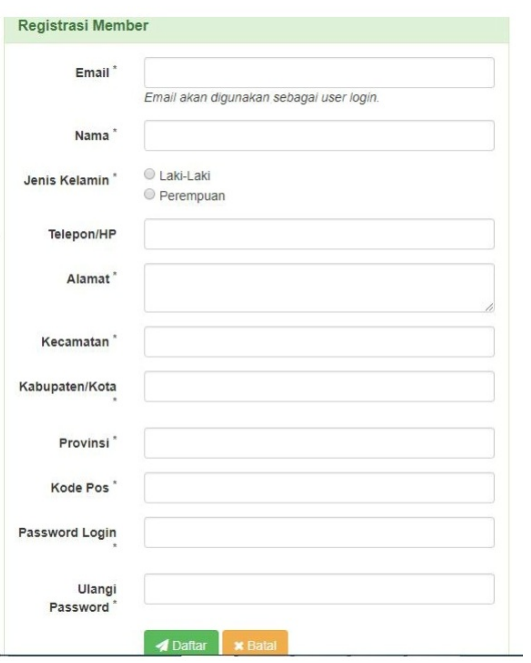

Sumber: Hasil Penelitian 2019

Gambar 8. Implemetasi Registrasi Member 


\section{c. Login Member}

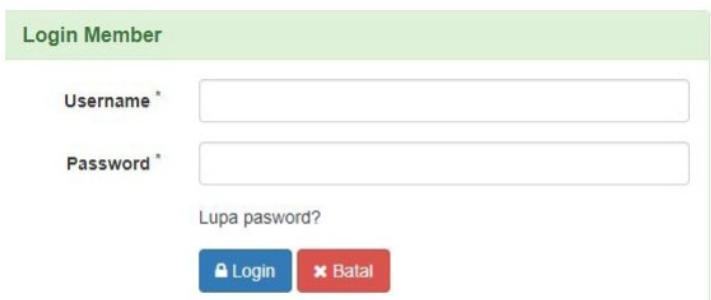

Sumber: Hasil Penelitian 2019

Gambar 9. Implementasi Login Member

d. Formulir Konfirmasi Pembayaran

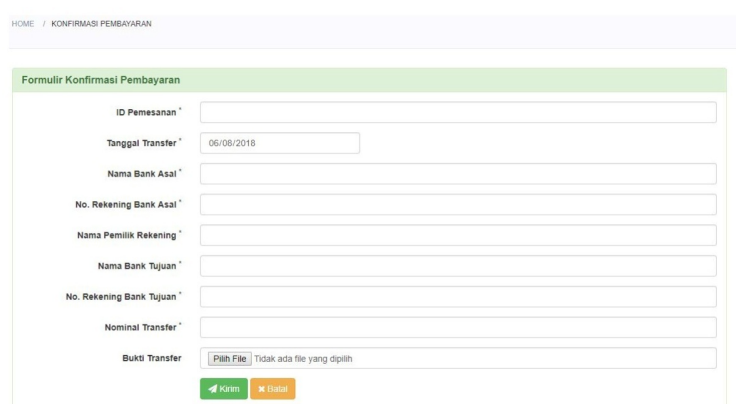

Sumber: Hasil Penelitian 2019

Gambar 10. Implementasi Transaksi Penjualan

e. Login Administrator

Sumber: Hasil Penelitian 2019

Gambar 11. Implementasi Login Administrator

\section{Pengujian Unit}

a. Pengujian Terhadap Registrasi Member Tabel 1. Pengujian Terhadap Registrasi

\begin{tabular}{|c|c|c|c|c|c|}
\hline $\begin{array}{l}\mathrm{N} \\
\mathrm{O}\end{array}$ & $\begin{array}{c}\text { Skenario } \\
\text { Pengujian }\end{array}$ & $\begin{array}{l}\text { Text } \\
\text { Case }\end{array}$ & $\begin{array}{l}\text { Hasil Yang } \\
\text { Diharapkan }\end{array}$ & $\begin{array}{c}\text { Hasil } \\
\text { Pengujian }\end{array}$ & $\begin{array}{l}\text { Kesimp } \\
\text { ulan }\end{array}$ \\
\hline 1 & $\begin{array}{l}\text { Nama lengkap } \\
\text { di isi angka }\end{array}$ & $\begin{array}{l}\text { Nama } \\
\text { lengka } \\
\text { p: di isi } \\
\text { angka }\end{array}$ & $\begin{array}{l}\text { Sistem tidak } \\
\text { mau } \\
\text { menyimpan } \\
\text { data }\end{array}$ & $\begin{array}{c}\text { Sesuai } \\
\text { Harapan }\end{array}$ & Valid \\
\hline 2 & $\begin{array}{l}\text { Nama lengkap } \\
\text { di isi huruf }\end{array}$ & $\begin{array}{l}\text { Nama } \\
\text { lengka } \\
\text { p: di isi } \\
\text { huruf }\end{array}$ & $\begin{array}{l}\text { Sistem akan } \\
\text { menyimpan } \\
\text { data }\end{array}$ & $\begin{array}{l}\text { Sesuai } \\
\text { Harapan }\end{array}$ & Valid \\
\hline 3 & $\begin{array}{l}\text { Telepon/HP di } \\
\text { isi angka }\end{array}$ & $\begin{array}{l}\text { Telepo } \\
\mathrm{n} / \mathrm{HP:} \\
\text { di isi } \\
\text { angka }\end{array}$ & $\begin{array}{l}\text { Sistem tidak } \\
\text { mau } \\
\text { menyimpan } \\
\text { data }\end{array}$ & $\begin{array}{l}\text { Sesuai } \\
\text { Harapan }\end{array}$ & Valid \\
\hline 4 & $\begin{array}{l}\text { Telepon/HP di } \\
\text { isi huruf }\end{array}$ & $\begin{array}{l}\text { Telepo } \\
\text { n/HP: } \\
\text { di isi } \\
\text { huruf }\end{array}$ & $\begin{array}{l}\text { Sistem akan } \\
\text { menyimpan } \\
\text { data }\end{array}$ & $\begin{array}{l}\text { Sesuai } \\
\text { Harapan }\end{array}$ & Valid \\
\hline
\end{tabular}

Sumber: Hasil Penelitian 2019

b. Pengujian Terhadap Konfirmasi Pembayaran Tabel 2. Pengujian Terhadap Konfirmasi Pembayaran

\begin{tabular}{|c|c|c|c|c|c|}
\hline No & $\begin{array}{l}\text { Skenario } \\
\text { Penujian }\end{array}$ & $\begin{array}{l}\text { Text } \\
\text { Case }\end{array}$ & $\begin{array}{l}\text { Hasil Yang } \\
\text { Diharapkan }\end{array}$ & $\begin{array}{c}\text { Hasil } \\
\text { Pengujian }\end{array}$ & $\begin{array}{c}\text { Kesimpul } \\
\text { an }\end{array}$ \\
\hline 1. & $\begin{array}{l}\text { Nomor } \\
\text { rekening } \\
\text { bank } \\
\text { asal di isi } \\
\text { huruf }\end{array}$ & $\begin{array}{l}\text { Nomor } \\
\text { rekening } \\
\text { bank } \\
\text { asal: di } \\
\text { isi huruf }\end{array}$ & $\begin{array}{l}\text { Sistem tidak } \\
\text { mau } \\
\text { menyimpan } \\
\text { data }\end{array}$ & $\begin{array}{c}\text { Sesuai } \\
\text { Harapan }\end{array}$ & Valid \\
\hline 2. & $\begin{array}{l}\text { Nomor } \\
\text { rekening } \\
\text { bank } \\
\text { asal di isi } \\
\text { angka }\end{array}$ & $\begin{array}{l}\text { Nomor } \\
\text { rekening } \\
\text { bank } \\
\text { asal: di } \\
\text { isi angka }\end{array}$ & $\begin{array}{l}\text { Sistem akan } \\
\text { menyimpan } \\
\text { data }\end{array}$ & $\begin{array}{l}\text { Sesuai } \\
\text { Harapan }\end{array}$ & Valid \\
\hline
\end{tabular}

ISSN: 2338-9761 (Online), 2338-8145 (Print)

\begin{tabular}{|c|c|c|c|c|c|}
\hline 3. & $\begin{array}{l}\text { Nama } \\
\text { pemilik } \\
\text { rekening } \\
\text { di isi } \\
\text { angka }\end{array}$ & $\begin{array}{l}\text { Nama } \\
\text { pemilik } \\
\text { rekening: } \\
\text { di isi } \\
\text { angka }\end{array}$ & $\begin{array}{l}\text { Sistem tidak } \\
\text { mau } \\
\text { menyimpan } \\
\text { data }\end{array}$ & $\begin{array}{l}\text { Sesuai } \\
\text { Harapan }\end{array}$ & Valid \\
\hline 4. & $\begin{array}{l}\text { Nama } \\
\text { pemilik } \\
\text { rekening } \\
\text { di isi } \\
\text { huruf }\end{array}$ & $\begin{array}{l}\text { Nama } \\
\text { pemilik } \\
\text { rekening: } \\
\text { di isi } \\
\text { huruf }\end{array}$ & $\begin{array}{l}\text { Sistem akan } \\
\text { menyimpan } \\
\text { data }\end{array}$ & $\begin{array}{c}\text { Sesuai } \\
\text { Harapan }\end{array}$ & Valid \\
\hline 5. & $\begin{array}{l}\text { Nomor } \\
\text { rekening } \\
\text { bank } \\
\text { tujuan di } \\
\text { isi huruf }\end{array}$ & $\begin{array}{l}\text { Nomor } \\
\text { rekening } \\
\text { bank } \\
\text { tujuan: di } \\
\text { isi huruf }\end{array}$ & $\begin{array}{l}\text { Sistem tidak } \\
\text { mau } \\
\text { menyimpan } \\
\text { data }\end{array}$ & $\begin{array}{l}\text { Sesuai } \\
\text { Harapan }\end{array}$ & Valid \\
\hline 6. & $\begin{array}{l}\text { Nomor } \\
\text { rekening } \\
\text { bank } \\
\text { tujuan di } \\
\text { isi angka }\end{array}$ & $\begin{array}{l}\text { Nomor } \\
\text { rekening } \\
\text { bank } \\
\text { tujuan: di } \\
\text { isi angka }\end{array}$ & $\begin{array}{l}\text { Sistem akan } \\
\text { menyimpan } \\
\text { data }\end{array}$ & $\begin{array}{l}\text { Sesuai } \\
\text { Harapan }\end{array}$ & Valid \\
\hline 7. & $\begin{array}{l}\text { Jumlah } \\
\text { transfer } \\
\text { di isi } \\
\text { huruf }\end{array}$ & $\begin{array}{l}\text { Jumlah } \\
\text { transfer: } \\
\text { di isi } \\
\text { huruf }\end{array}$ & $\begin{array}{l}\text { Sistem tidak } \\
\text { mau } \\
\text { menyimpan } \\
\text { data }\end{array}$ & $\begin{array}{l}\text { Sesuai } \\
\text { Harapan }\end{array}$ & Valid \\
\hline 8. & $\begin{array}{l}\text { Jumlah } \\
\text { transfer } \\
\text { di isi } \\
\text { angka }\end{array}$ & $\begin{array}{l}\text { Jumlah } \\
\text { transfer: } \\
\text { di isi } \\
\text { angka }\end{array}$ & $\begin{array}{l}\text { Sistem akan } \\
\text { menyimpan } \\
\text { data }\end{array}$ & $\begin{array}{c}\text { Sesuai } \\
\text { Harapan }\end{array}$ & Valid \\
\hline
\end{tabular}

Sumber: Hasil Penelitian 2019

\section{KESIMPULAN}

Berdasarkan hasil analisa dan pembahasan, maka dapat disimpulkan:

1. Dengan adanya website ini mampu meningkatkan jumlah pembeli, mampu meningkatkan penjualan dan daya saing usaha.

2. Dengan adanya website ini dapat membantu konsumen dalam mengakses informasi bibit durian kapan saja dan dimana saja dengan mudah.

3. Dengan memanfaatkan media informasi berbasis web dapat membantu Kelompok Tani Bibit Durian Maju Makmur dalam memperluas jangkauan pemasaran.

4. Dengan adanya pengembangan website ini dapat membantu memasarkan dan menyampaikan informasi produk dan harga bibit durian pada konsumen.

Agar perancangan website ini bisa bekerja optimal, maka ada beberapa saran yang penulis berikan yaitu untuk menghindari terjadinya kejahatan di dunia maya (cyber crime) admin diharapkan melakukan penggantian password secara berkala pada website ini agar dapat terjaga keamanannya. Serta mengimplementasikan aplikasi pada platform mobile.

\section{REFERENSI}

Aprizal, M. (2016). Pengembangan Sistem Informasi Penjualan Benih Padi Pada Balai Pengkajian Teknologi Pertanian. Techno.COM, 15(2), 151-158. Retrieved from

http://publikasi.dinus.ac.id/index.php/techn oc/article/view/1152

Arman Arman, Elizamiharti, M. S. (2019). Analisa dan Perancangan Sistem Informasi Penjualan Tanaman Hias Berbasis Online Sebagai Media Promosi 
Bagi Salman KS Flowers. Jurnal Teknologi Informasi \& Komunikasi Digital Zone, 10(1), 64-76. Retrieved from https://journal.unilak.ac.id/index.php/dz/art icle/view/2346

Hariyanto, D., \& Meidiany, T. (2018). Sistem Informasi Akademik Sekolah Berbasis Website (Studi Kasus: SMK 11 Maret Jakarta). Jurnal Swabumi, 6(1), 98-103. https://doi.org/10.31294/swabumi.v6i1.332 2

Juniansyah, B. D., Susanto, E. R., \& Wahyudi, A. D. (2020). Pembuatan E-Commerce Pemesanan Jasa Event Organizer Untuk Zero Seven Entertaiment. Jurnal TEKNO KOMPAK, 14(1), 41-46. Retrieved from https://ejurnal.teknokrat.ac.id/index.php/te knokompak/article/view/499

Nasser, R. (2017). Pengembangan Website Kantor Perkebunan Pengolahan Bibit Unggul Kakao Kab. Luwu Utara. Jurnal Ilmiah d'Computare, 7, 44-53. Retrieved from

https://journal.uncp.ac.id/index.php/compu tare/article/view/506

Rhiyan Edyal, B. E. P. (2016). Aplikasi Penjualan Kelapa Sawit Berbasis Web pada KUD di Kab. Dharmasraya. Jurnal Multinetics, 2(2), 30-33. Retrieved from http://jurnal.pnj.ac.id/index.php/multinetics/ article/view/1044

Sari, H. E., \& Prasetiawati, R. (2020). Analisis Sistem Informasi Customer Relationship Management Berbasis Web Pada PT. INOVATIF TEKNIK MESINDO. Technomedia Journal (TMJ), 5(1), 1-13. Retrieved from https://ijc.ilearning.co/index.php/TMJ/articl e/view/881 